\title{
¿Economic Valuation of Coccidioidomycosis (Valley Fever) Projections in the United States in Response to Climate Change $\mathscr{D}$
}

\author{
Morgan E. Gorris, ${ }^{\mathrm{a}}$ James E. Neumann, ${ }^{\mathrm{b}}$ Patrick L. Kinney, ${ }^{\mathrm{c}}$ Megan Sheahan, ${ }^{\mathrm{b}}$ And Marcus C. Sarofim ${ }^{\mathrm{d}}$ \\ ${ }^{a}$ Los Alamos National Laboratory, Los Alamos, New Mexico \\ ${ }^{\mathrm{b}}$ Industrial Economics, Inc., Cambridge, Massachusetts \\ ${ }^{\mathrm{c}}$ Department of Environmental Health, School of Public Health, Boston University, Boston, Massachusetts \\ ${ }^{\mathrm{d}}$ U.S. Environmental Protection Agency, Washington, D.C.
}

(Manuscript received 31 March 2020, in final form 22 August 2020)

\begin{abstract}
Coccidioidomycosis, or valley fever, is an infectious fungal disease currently endemic to the southwestern United States. Symptoms of valley fever range in severity from flu-like illness to severe morbidity and mortality. Warming temperatures and changes in precipitation patterns may cause the area of endemicity to expand northward throughout the western United States, putting more people at risk for contracting valley fever. This may increase the health and economic burdens from this disease. We developed an approach to describe the relationship between climate conditions and valley fever incidence using historical data and generated projections of future incidence in response to both climate change and population trends using the Climate Change Impacts and Risk Analysis (CIRA) framework developed by the U.S. Environmental Protection Agency. We also developed a method to estimate economic impacts of valley fever that is based on case counts. For our 2000-15 baseline time period, we estimated annual medical costs, lost income, and economic welfare losses for valley fever in the United States were $\$ 400,000$ per case, and the annual average total cost was $\$ 3.9$ billion per year. For a high greenhouse gas emission scenario and accounting for population growth, we found that total annual costs for valley fever may increase up to $164 \%$ by year 2050 and up to $380 \%$ by 2090 . By the end of the twenty-first century, valley fever may cost $\$ 620,000$ per case and the annual average total cost may reach $\$ 18.5$ billion per year. This work contributes to the broader effort to monetize climate change-attributable damages in the United States.
\end{abstract}

SIGNIFICANCE STATEMENT: Valley fever is a disease that is most common in the hot and arid regions of the southwestern United States and already costs billions of dollars in disease treatment and lost worker productivity, with consequences that include premature death. The purpose of our work was to estimate the impact that climate change may have on the total costs to society from valley fever. We found that there will likely be a tripling of valley fever cases in the future and that the average cost per case will increase, causing total yearly costs to rise from $\$ 3.9$ billion per year (2000-15 estimate) to $\$ 18.5$ billion per year by 2090 . Our estimations of the future number of valley fever cases and total costs may help to inform public health decision-makers to begin monitoring the number of disease cases and prepare appropriate medical supplies.

KEYWORDS: Climate services; Decision support; Disease; Economic value; Planning; Risk assessment

\section{Introduction}

Coccidioidomycosis, otherwise known as valley fever, is an infectious fungal disease that humans can contract by inhaling Coccidioides spp. fungal spores from the environment. These fungal spores can become airborne from any type of soil disturbance and travel in dust, especially under dry conditions. Currently, the area endemic to valley fever is mostly limited to the southwestern United States (Centers for Disease Control and Prevention; CDC 2019a). However, increasing temperatures and

¿ Denotes content that is immediately available upon publication as open access.

Supplemental information related to this paper is available at the Journals Online website: https://doi.org/10.1175/WCAS-D-200036.s1.

Corresponding author: Morgan Gorris, mgorris@lanl.gov shifts in precipitation patterns as a result of climate change (Hayhoe et al. 2018) may broaden the endemic area, causing a northward expansion throughout much of the western United States (Gorris et al. 2019). This expansion would put new communities at risk for contracting valley fever, potentially increasing the health and economic burdens from his disease.

People with valley fever may experience a range of clinical manifestations from self-limiting respiratory illness, pneumonia, or meningeal infection to a disseminated form of the disease that can cause skin abscesses and life-threatening meningitis (Nguyen et al. 2013). Approximately 40\% of people who inhale Coccidioides ssp. spores will be symptomatic (Smith and Beard 1946). In the United States, there are on average 200 deaths from valley fever each year (CDC 2019b). Valley fever results in both direct and indirect costs to patients: direct costs include diagnosis, treatment, and follow-up, whereas indirect costs include productivity losses (Wilson et al. 2019). In California in 2017, lifetime costs from valley fever were estimated to be $\$ 94,000$ per person, with $\$ 58,000$ in direct costs and $\$ 36,000$ in indirect costs, totaling $\$ 700$ million for 
the state (Wilson et al. 2019), without including welfare economic costs associated with premature mortality.

A method was recently developed to estimate where valley fever may be endemic and the number of disease cases in response to climate change (Gorris et al. 2019). This allowed for the first estimations of the future medical costs of valley fever solely based on hospitalization costs, but disregarded other direct and indirect costs of the disease as well as changes in human population. We expanded upon this analysis to estimate the economic valuation attributed to valley fever health impacts using the Climate Change Impacts and Risk Analysis (CIRA) framework developed by the U.S. Environmental Protection Agency (EPA) (EPA 2015, 2017a). The CIRA framework uses a consistent set of climate and socioeconomic scenarios and assumptions to quantify and monetize the effects of climate change on various U.S. sectors, including human health, infrastructure, and water resources (Martinich and Crimmins 2019; EPA 2017a). We considered the costs of valley fever in response to both a moderate greenhouse gas emissions scenario, representative concentration pathway (RCP) 4.5, and a high greenhouse gas emissions scenario, RCP8.5 (Moss et al. 2010). We also accounted for future changes in human population and gross domestic product (GDP).

Our analysis consisted of three steps. First, we used a previously constructed climate-constrained niche model (Gorris et al. 2019) and downscaled climate projections to estimate the valley fever endemic area for years 2010, 2030, 2050, 2070, and 2090. Second, we used statistical relationships between contemporary precipitation, temperature, and a previously compiled valley fever incidence dataset, all for 2000-15, to create a predictive model of the number of valley fever cases within the counties we project to be endemic. Last, we used a set of health-cost indirect losses and economic welfare damage functions to quantify the per case and total costs of valley fever in response to climate change throughout the twenty-first century. The results from this work contribute to the broader effort to systematically quantify and monetize climate changeattributable damages in the United States, which in the past has informed the U.S. National Climate Assessments (Reidmiller et al. 2018) and forms the basis for sustained assessment of the impacts of climate change (Moss et al. 2019).

\section{Data and methods}

\section{a. Valley fever case data}

To both estimate the contemporary levels of disease incidence and calculate a baseline cost estimate of the health impacts from valley fever, we used a valley fever case dataset previously compiled for the southwestern United States (Gorris et al. 2018). This dataset included monthly, county-level cases for 2000-15 in Arizona, California, Nevada, New Mexico, and Utah. Each valley fever case has a date corresponding to the month and year when the diagnosing health institution submitted the official case report. We calculated the annual valley fever incidence rate for each county to compare with mean annual climate conditions for each year between 2000 and 2015. We calculated incidence rate as cases per 100000 population, using county-level human population data.

\section{b. Human population data}

To calculate contemporary valley fever disease incidence, we gathered county-level human population data from the U.S. Census Bureau intercensal population estimates for 2000-15 (U.S. Census Bureau 2011, 2020). When we estimate the number of people currently living within the projected endemic region and the number of contemporary valley fever cases for our 2000-15 baseline time period, we use 2010 population estimates from U.S. Census Bureau decadal survey. To estimate the future number of people living within the projected endemic regions for valley fever and to calculate future projections of disease case counts, we used human population projections from the Integrated Climate and Land Use Scenarios, version 2 (ICLUSv2), model developed by the EPA (Bierwagen et al. 2010; EPA 2017b). The ICLUSv2 population estimates follow the shared socioeconomic pathways 2 scenario in which there is moderate population growth in the United States throughout the twenty-first century, assuming moderate levels of fertility, mortality, and international immigration (O'Neill et al. 2014). This scenario only focuses on socioeconomic development and does not incorporate climate change or future climate policies. These county-level population estimates are based on disaggregated national population projections from the Median Variant Projection of the United Nations's 2015 World Population Prospects dataset (United Nations 2015). The ICLUSv2 model also accounts for some impacts of climate change in the development of future county-level population size. Human population and demographic (i.e., age, gender, and race) projections are available in 5-yr estimates. To match with our projections of valley fever endemicity, we calculated estimates of future population for 2030 (the average of 2020-39), 2050 (the average of 2040-59), 2070 (the average of 2060-79), and 2090 (the average of 2080-99).

\section{c. Contemporary climate data}

To estimate the current spatial extent of valley fever endemicity following Gorris et al. (2019), we used surface temperature and precipitation data from the Precipitation-Elevation Regressions on Independent Slopes Model (PRISM; Daly et al. 2008), available as 4-km gridded products. We calculated county-level climate averages by spatially averaging the gridded PRISM climate data within each county using QGIS (https://www.qgis.org). We obtained county shapefiles from the U.S. Census Bureau (https://www.census.gov/geo/mapsdata/data/tiger-line.html). We calculated mean annual temperature and annual precipitation values for each county and each year over our baseline time period (2000-15) to compare with annual valley fever incidence.

\section{d. CIRA framework climate data and projections}

To estimate the area endemic to valley fever throughout the twenty-first century, we used climate projections following the CIRA framework developed by the EPA (EPA 2015, 2017a; Martinich and Crimmins 2019). We used downscaled climate projections from the Localized Constructed Analogs (LOCA) dataset (Pierce et al. 2015) for six Earth system models participating in phase 5 of the Coupled Model Intercomparison 
Project (CMIP5; Taylor et al. 2011): CanESM2 (von Salzen et al. 2013), CCSM4 (Gent et al. 2011), GFDL CM3 (Donner et al. 2011), GISS-E2-R (Schmidt et al. 2006), HadGEM2-ES (Collins et al. 2011), and MIROC5 (Watanabe et al. 2010). These models project a range of plausible outcomes based on varying assumptions and parameterizations of the Earth system's response to greenhouse gas forcing. We gathered monthly output for surface precipitation, maximum surface air temperature, and minimum surface air temperature and regridded the data to $1 / 8^{\circ} \times 1 / 8^{\circ}$ resolution from $1 / 16^{\circ} \times 1 / 16^{\circ}$ resolution. We calculated the mean surface air temperature by averaging the output of maximum and minimum surface air temperatures.

We averaged the raw, gridded LOCA output to calculate mean annual temperature and precipitation for 20-yr means centered around four eras: 2030 (the average of 2020-39), 2050 (the average of 2040-59), 2070 (the average of 2060-79), and 2090 (the average of 2080-99). We calculated county-level climate averages by spatially averaging the mean annual LOCA climate data within each county for the four eras and six Earth system models, separately.

We analyzed both RCP8.5, a high climate warming scenario, and RCP4.5, a moderate climate warming scenario. The RCP8.5 climate scenario represents high greenhouse gas concentrations in which radiative forcing rises to $8.5 \mathrm{~W} \mathrm{~m}^{-2}$ by 2100 relative to 1750 and global temperature is projected to increase by $3^{\circ}-5.5^{\circ} \mathrm{C}$ by 2100 relative to the $1986-2005$ average. The RCP4.5 climate scenario represents lower greenhouse gas concentrations in which radiative forcing stabilizes at $4.5 \mathrm{~W} \mathrm{~m}^{-2}$ shortly after 2100 , and global temperature is projected to increase by $1.1^{\circ}-2.6^{\circ} \mathrm{C}$ by 2100 (van Vuuren et al. 2011).

\section{e. Projections of valley fever endemic regions}

We used a climate-constrained niche model following the methods outlined in Gorris et al. (2019) to estimate the areas that may be endemic to valley fever throughout the twenty-first century. This climate-constrained niche model defines a county as potentially endemic to valley fever if it has a mean annual temperature meeting or exceeding $10.7^{\circ} \mathrm{C}$ and mean annual precipitation meeting or below $600 \mathrm{~mm} \mathrm{yr}^{-1}$. We used the PRISM climate data averaged from 2000 to 2015 to define our baseline region endemic to valley fever, in parallel with the methods of Gorris et al. (2019; Fig. 1a). We estimate 217 counties across 12 states as currently potentially endemic for valley fever (Fig. 1a); the endemic region primarily spans the southwestern United States. Our estimated endemic region captures all the counties with elevated levels of contemporary valley fever incidence ( $>21.0$ cases per 100000 population averaged from 2011 to 2017) as reported by the CDC (CDC 2019a).

Then, we used the LOCA climate projections to estimate the areas that may become endemic for years 2030, 2050, 2070, and 2090 for both RCP4.5 and RCP8.5. As an uncertainty metric, we report the level of agreement among the six models that each county will become endemic to valley fever. To provide an additional measure of uncertainty, we calculated the standard deviation across the six Earth system models for each valley fever statistic. Last, we report the individual model projections of the number of counties endemic to valley fever for each of the time periods.

\section{f. Projections of future valley fever incidence}

We used the statistical relationships between mean annual temperature, annual precipitation, and valley fever incidence between 2000 and 2015 at the county level to estimate future valley fever incidence rates in the counties we project to be endemic. We used annual climate data as input to our model to better capture interannual variability in the number of disease cases. First, we screened counties to use in our model development to only include counties that met our valley fever endemicity thresholds (i.e., temperature greater than $10.7^{\circ} \mathrm{C}$ and precipitation less than $600 \mathrm{~mm} \mathrm{yr}^{-1}$ ) in any one year between 2000 and 2015. Of the 152 counties in our original case dataset across Arizona, California, Nevada, New Mexico, and Utah, this criterion restricted our final sample to 109 potentially endemic counties within the five states (1744 observations across 16 years).

Using the climate and incidence data from these 109 counties, we then employed a linear ordinary least squares (OLS) regression function to estimate the county-level valley fever incidence rate (cases per 100000 population) in county $i$ in year $t$ :

$$
\mathrm{VFI}_{i t}=\beta_{0 i t}+\beta_{1 i t} P_{i t}+\beta_{2 i t} T_{i t}+\tau_{t}+\epsilon_{i t},
$$

where $P$ is annual precipitation, $T$ is mean annual temperature, $\tau$ are year fixed effects (where the most recent year, 2015, serves as the base), and $\epsilon$ is the error term. We used year fixed effects to control for any potential reporting bias in early years, when awareness of valley fever was more limited and misdiagnosis may have been more common; indeed, the year fixed effects were lower for the earlier time period 2000-03. To account for correlation across observations within a given county, we clustered standard errors at the county level (e.g., Eicker 1967; Huber 1967). Our final predictive model of valley fever incidence rate was

$$
\mathrm{VFI}_{i t}=-\underset{(14.471)^{* * *}}{36.017} \underset{(0.004)^{* * * * *}}{0.012} P_{i t}+\underset{(1.148)^{* * * *}}{3.562} T_{i t}+\tau_{t}+\epsilon_{i t}
$$

where clustered standard errors are presented below the coefficients in parentheses and level of statistical significance is denoted by asterisks (two asterisks for the 95th percentile and three asterisks for the 99th percentile). As anticipated, an increase in temperature is correlated with higher valley fever incidence, whereas there is a negative relationship between precipitation and valley fever incidence. The large negative constant term, roughly 10 times the magnitude of the per degree temperature coefficient, is consistent with the findings of the niche model for endemicity, in that we expect small to negligible levels of incidence in counties that do not meet the endemicity thresholds (average annual temperatures below $10.7^{\circ} \mathrm{C}$ or total annual precipitation above $600 \mathrm{~mm} \mathrm{yr}^{-1}$ ). The constant term, combined with the temperature term, therefore operates something like an effect threshold, because in applying the function we set negative estimates of incidence to zero. We considered and ultimately rejected a range of other model specifications and estimators (Tables S1 and S2 in the online supplemental material) most of which offered the same statistical relationships between precipitation, temperature, and valley fever incidence. 
a) Potential valley fever endemic region

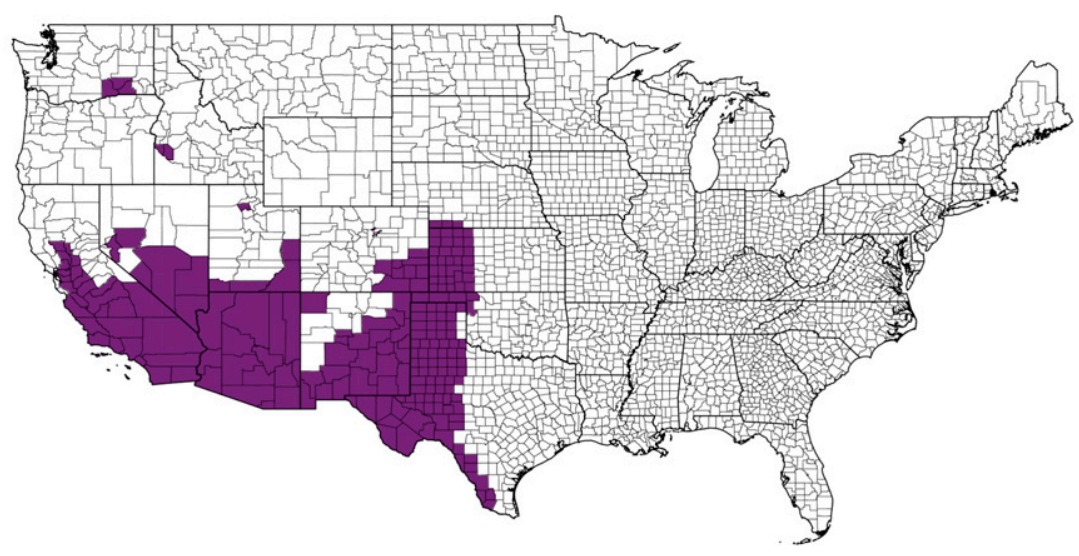

b) Estimated levels of valley fever incidence
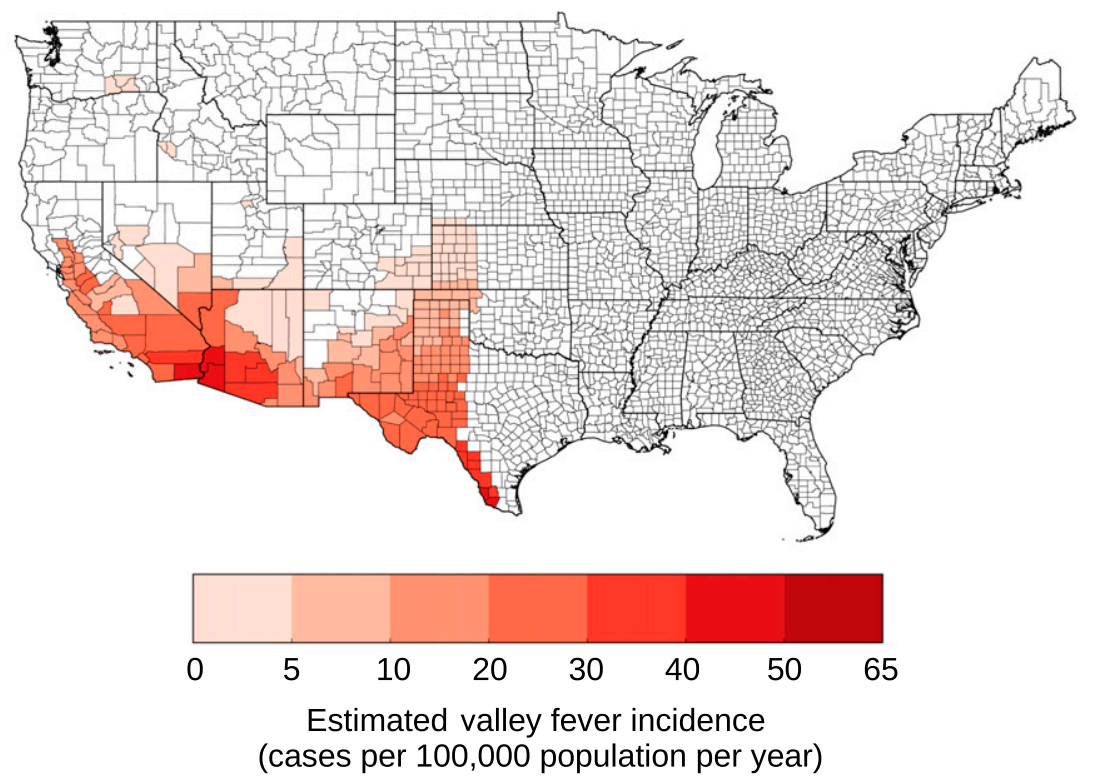

FIG. 1. (a) Counties our climate-constrained niche model identifies as potentially endemic (with a mean annual temperature greater than or equal to $10.7^{\circ} \mathrm{C}$ and a mean annual precipitation level less than or equal to $600 \mathrm{~mm} \mathrm{yr}^{-1}$ ) for our baseline time period from 2000 to 2015 are colored in purple. (b) The estimated levels of valley fever incidence (cases per 100000 population per year) for our baseline time period. We calculated these values by applying our OLS model to annual climate conditions from 2000 to 2015 and taking the mean incidence across the 16 years.

Our estimation of contemporary valley fever incidence places the highest levels of incidence in southern California and western Arizona (Fig. 1b). Our model overpredicts low incidence counties in the hottest and driest areas of the southwest, including southern California and western Arizona. It underpredicts the highest incidence counties in known valley fever hotspots, such as Maricopa County, Arizona (including Phoenix), and Kern County, California (including Bakersfield). Before using our preferred model to predict the number of future cases, we confirmed the model adequately captures countylevel incidence over our baseline time period by comparing the predicted total number of total valley fever cases from 2000 to
2015 with observations in our 109-county sample. In particular, the largest residuals in our OLS model are associated with the county-year combinations that have the highest observed valley fever incidence (i.e., the metro areas including BakersfieldDelano, California, and Phoenix-Mesa-Glendale, Arizona), suggesting that our model is unable to predict observed valley fever incidence in the areas with the highest incidence levels. However, on aggregate the model predicts 153931 cases (using 2010 population) in these 109 counties between 2000 and 2015 as compared with 145068 observed cases.

We used Eq. (2) to predict future county-level valley fever incidence using estimates of future precipitation and temperature 
following the CIRA framework. We mapped the regression model results to counties where at least four of the six Earth system models predicted the climate will meet the endemicity thresholds. In addition, we include individual model estimates of valley fever incidence in the online supplemental material.

\section{g. Health impacts analysis and economic valuation}

To quantify health impacts, we converted our estimations of valley fever incidence rates as output from our regression model to case counts using population estimates. We estimated the economic value of projected health impacts based on recommendations in federal guidance for economic analyses (EPA 2014) as well as our own research. The direct medical costs associated with valley fever include hospitalizations, trips to the emergency room, and physician visits. Consistent with federal guidance (including EPA 2018a), we do not project changes in real medical treatment costs over time, though our own analysis of medical cost data (see the online supplemental material) and other studies (Wilson et al. 2019) do suggest that treatment costs for valley fever may be increasing over time-we conclude at this point that the existing trends in medical treatment costs, which are complicated by known underreporting of valley fever cases, and likely changes over time in provider knowledge of a correct valley fever diagnosis, are not yet reliable enough to project for the twenty-first century. Our model also considers the indirect costs associated with productivity losses from time spent in the hospital, emergency room, and physician's office. Indirect costs grow over time with our projection of the wage rate, which is based on a projection of national GDP per capita described more fully in EPA (2017a). The rate of growth for real GDP per capita from this source over the 20152100 period is $1.77 \%$, with estimates declining over time from just over $2 \%$ in the $2020-30$ period to $1.3 \%$ in the $2090-2100$ period. These estimates are comparable to those used in Wilson et al. (2019), which use a different method.

To calculate total costs, first we estimate the percentage of valley fever cases that will result in each of these three outcome categories. We used historical rates from the Healthcare Cost and Utilization Project (HCUPnet) dataset for 2006-14, maintained by the Agency for Healthcare Research and Quality (AHRQ) - specifically the National Inpatient Sample (NIS) and Nationwide Emergency Department Sample (NEDS) and Gorris et al. (2019). For mortality rates, we used the CDC's Wide-Ranging Online Data for Epidemiologic Research (WONDER) Underlying Cause of Death and Multiple Cause of Death mortality databases, with deaths attributed to International Statistical Classification of Diseases and Related Health Problems (ICD) codes from 1999 to 2017 (CDC 2019c). Combined, these data sources suggest that $19 \%$ of valley fever cases will result in direct hospitalization, $8 \%$ in emergency room visits followed by discharge, $26 \%$ in emergency room visits followed by admittance to the hospital, $43 \%$ in physician visits, and $4 \%$ in death (where valley fever is either the primary or secondary contributor). ${ }^{1}$

\footnotetext{
${ }^{1}$ The sum of direct hospitalization $(19 \%)$ and hospital admittance indirectly through emergency room visits $(26 \%)$ is $45 \%$, which is the same value used in Gorris et al. (2019).
}

Then, we assign unit costs to each of these outcome categories. To value premature mortality, we use the "value of statistical life" (VSL); this value is used in EPA economic analyses that consider the "willingness to pay" of individuals, which accounts for the amounts individuals are willing to pay for small reductions in mortality risk. We account for changes in VSL throughout the twenty-first century as real income grows ("income elasticity" of willingness to pay). For mortality, we used the EPA's Guidelines for Preparing Economic Analyses, which recommends a VSL of $\$ 7.9$ million (2008 dollars) based on 1990 incomes (EPA 2014). To create a VSL using 2015 dollars and based on 2010 incomes, the standard value was adjusted for inflation and income growth based on the approach described in the EPA's Benefits Mapping and Analysis Program-Community Edition (BenMAP-CE) model and its documentation (EPA 2018a,b). The resulting value, $\$ 9.8$ million for 2010 (2015 dollars), was adjusted to future years by assuming an income (GDP per capita) elasticity of VSL of 0.4. We use projections of economic growth from the Emissions Predictions and Policy Analysis model (version 6; Chen et al. 2015) divided by estimations of human population using the ICLUSv2 population projections to calculate GDP per capita at a national scale. Applying this standard approach yields the following VSL values: $\$ 11.1$ million in 2030, $\$ 12.4$ million in 2050, \$13.8 million in 2070, and \$15.2 million in 2090 (in undiscounted 2015 dollars). As more recent literature favors a higher estimate of income elasticity of VSL (e.g., see Robinson et al. 2019), we also performed a sensitivity test using an elasticity of 1.0, reflecting proportional growth in VSL with gross domestic product per capita. Using an elasticity of 1.0 compared with 0.4 , our estimated costs associated with the mortality burdens are 16\% higher in 2030 and $87 \%$ higher in 2090 . The sensitivity analysis suggests that our valuation of the mortality endpoints may be conservative. We provide more information in the discussion section on the influence of this factor on overall estimates of the burden of valley fever incidence over time.

To value emergency room visits and hospitalizations, we queried the HCUPnet dataset; specifically, we used the NIS and NEDS datasets. We used International Classification of Diseases and Related Health Problems, Ninth Revision codes (ICD-9) for coccidioidomycosis defined under code 114 . We estimated the average cost of a hospital stay is $\$ 21,272$ (2015 dollars) and the average cost of an emergency room visit is $\$ 1,034$ (2015 dollars). We apply this hospitalization cost for both cases that were directly admitted to the hospital and cases that first sought emergency room care and then were admitted to the hospital. Our valuation estimates for valley fever focus only on the short-term effects (hospital admissions and emergency room visits) and therefore reflect the economic damages in the year of that case report only. To the extent that valley fever presents ongoing or lifetime medical costs that persist after the year of diagnosis, like antifungal therapy, our cost estimates are conservative.

We value physician office visits for valley fever using the values from food-borne illnesses as a proxy. Specifically, we apply the value calculated by the Economic Research Service (ERS) of the U.S. Department of Agriculture (USDA) for 
physician office visits on account of Salmonella. They construct an average per visit cost of \$140 (2015 dollars) (USDA 2014), which has also been applied to other food-borne illnesses (e.g., Hoffmann et al. 2012; Scallan et al. 2011). Applying the value from food-borne illnesses is a reasonable approach because the time spent in the physician's office is unlikely to vary tremendously by condition. The value associated with physician office visits, on a per case and total economic burden estimate, is the smallest component of our overall cost burden estimate. Therefore, minor variation in the actual cost of a physician visit is unlikely to significantly alter our overall results. Note that all direct costs for hospitalization, emergency room visits, and physician office visits represent the full resources costs of providing treatment to patients in the year of diagnosis; therefore, they include out-of-pocket costs incurred by patients and all costs of the provider treating those patients, regardless of who ultimately pays those costs (e.g., insurance, Medicare).

Productivity losses result from time spent in the hospital, physician's office, and emergency room. The NIS data from HCUPnet reveal the average length of a hospital stay for a valley fever case was 8 days in 2016. Data from the National Health Interview Survey (NHIS) show that people with salmonellosis who visited a physician lost an average of 1.6 days (Frenzen et al. 1999). We assume this estimate can be used as a proxy for the analogous time lost for physician visits for valley fever. For trips to the emergency room, we are unaware of time loss estimates that could be applied to valley fever. Instead, we transferred the estimate from the time loss associated with a physician's visit. To value this time, we use the median daily wage rate in BenMAP [obtained from the U.S. Census Bureau (2015) American Community Survey] of $\$ 172.80$ (2015 dollars) and adjust for future years using a per capita GDP adjustment factor.

Figure 2 provides a summary of the sequence of key steps in our analysis. We first screen counties as endemic to valley fever following that of Gorris et al. (2019). Then, we use our OLS model as our health impact function to estimate county-level valley fever incidence rates as a function of climatic factors. We repeat this two-stage projection of future incidence for the four future time eras using projections of climate from six Earth system models following the CIRA framework. After converting estimations of valley fever incidence to the number of disease cases, we then parse each case into five health outcome severity levels to estimate total health burden. Last, we value each health outcome using estimates of medical cost, lost income, and economic welfare losses to generate an estimate of total economic impact.

\section{Results}

\section{a. Projections of valley fever endemic regions}

We applied a climate-constrained niche model consistent with Gorris et al. (2019) to identify which counties may become endemic to valley fever in response to climate change. For the high climate warming RCP8.5 scenario, we found the area of endemicity will expand northward throughout the western United States (Fig. 3). This expansion is mostly driven by counties warming above the temperature threshold for endemicity. There is high model agreement that many of the southwestern counties will stay endemic throughout the twenty-first century. The extent of the northward expansion is most uncertain for 2070, where some climate models project the area of endemicity will reach the middle of the Great Plains region, while others project it may reach as far north as the U.S.-Canada border. However, by 2090, over half the models predict the climate along the U.S.-Canada border will be suitable for endemicity. For the moderate climate warming RCP4.5 scenario, the northward expansion was more limited throughout the twentyfirst century (Fig. S1 in the online supplemental material). More counties may become endemic in the rain shadow of the Sierra Nevada mountains, but the expansion throughout the Great Plains is not projected to meet the U.S.-Canada border by 2090.

On average, the number of endemic counties will increase by $117 \%$ from 217 counties in our baseline period to 471 counties by 2090 for the RCP8.5 climate scenario (Table 1). The number of endemic states will also increase from 12 in our baseline period to 19 by 2090. All six Earth system models project a continuous increase in the number of endemic counties through time. There is a wide range, however, in the number of endemic counties projected by each of the six models. By 2090, the most conservative model (GISS, which tends to project more moderate warming in the western United States) estimates 364 counties (18 states) to be endemic, while the least conservative model (MIROC, which tends to project hotter and particularly drier conditions than the other models in our ensemble) estimates 584 counties ( 20 states) to be endemic. For RCP4.5, the number of endemic counties will increase by $71 \%$ to 371 counties and 18 endemic states by 2090 (Table S3 in the online supplemental material).

Differences in the projections of both the number of endemic counties and the location of the endemic counties results in a spread in the estimated number of people living in the valley fever endemic region (Table 2). All six Earth system models project an overall increase in the population living within the endemic region from baseline to 2090. Taking into account population growth using ICLUSv2 population estimates, 94.2 million people are projected to live in the endemic region by 2090 . This is a $93 \%$ increase in the people who may be at risk for contracting valley fever relative to our baseline period due to the combined effects of climate change and increasing population. The spread in the projections of human population living within the endemic counties increases through time, similar to the number of endemic counties. In the constant population analysis, four models (CanESM2, CCSM4, GFDL CM3, and HadGEM2-ES) do not project continuously increasing levels of human population living within the endemic region; this is due to high population counties falling out of the endemic region due to regional increases in precipitation, especially in California. On average, considering constant population levels, 54.2 million people may live in the valley fever endemic region by 2090. For RCP4.5, 94.8 million people are projected to live in the valley fever endemic region by 2090 considering ICLUSv2 future population estimates (Table S4 in the online supplemental material). This is a slightly larger population than projected for the RCP8.5 scenario, which is driven by a few large 


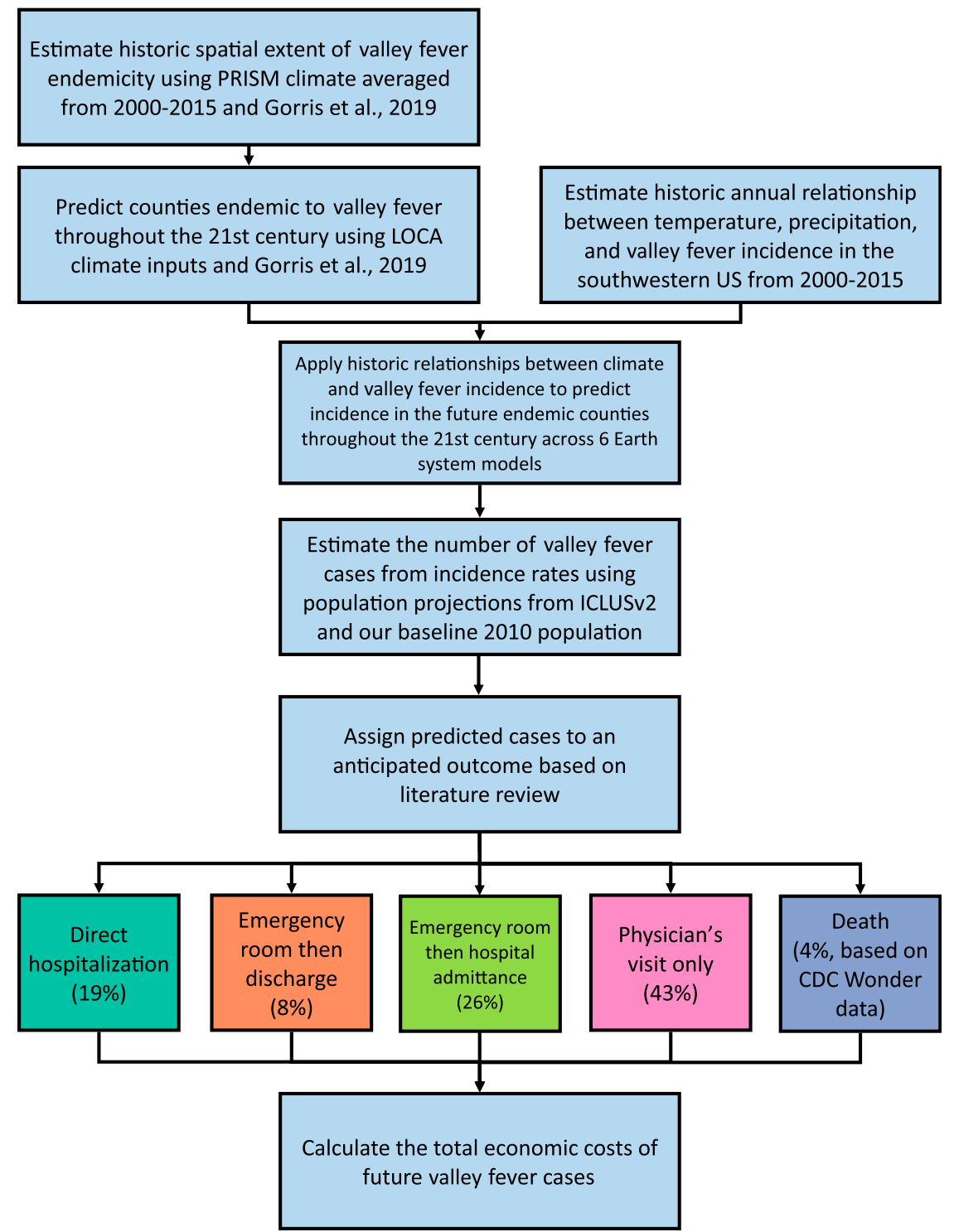

FIG. 2. Our analytical workflow to calculate the total economic costs of valley fever.

population counties that remain within the endemic region. So although the size of the valley fever endemic areas will differ, the total population at risk is projected to be similar.

\section{b. Projections of valley fever incidence and cases}

We estimated future valley fever incidence by applying an OLS regression model (described in section $2 \mathrm{f}$ ) to counties expected to be endemic. We calculated the average incidence between the six models and applied it to counties that at least four out of the six Earth system models projected may be endemic for that time period. For the RCP8.5 climate scenario, the highest valley fever incidence is projected to be in the southwestern United States (Fig. 4). Through time, the incidence levels in the southwestern United States increase and higher incidence begins to expand farther north following the expansion of the endemic region. The locations of higher incidence were similar for the RCP4.5 climate scenario, though restricted to the smaller projected endemic area (Fig. S2 in the online supplemental material). We also calculated the incidence using each of the individual Earth system model climate projections for both the RCP4.5 and RCP8.5 climate scenarios (Figs. S3-S8 in the online supplemental material).

We transformed incidence to the number of valley fever cases using both population projections from the ICLUSv2 dataset and baseline estimates of human population (2010; Table 3). For the RCP8.5 climate scenario averaged across the six Earth system model projections, we found that the number of cases per year by the end of the twenty-first century may increase by $220 \%$ considering anticipated population growth and by $79 \%$ disregarding changes in population (Table 3 ). Analogously, for the RCP4.5 climate scenario, the number of valley fever cases per year may increase by $163 \%$ considering projected population 
a. 2030
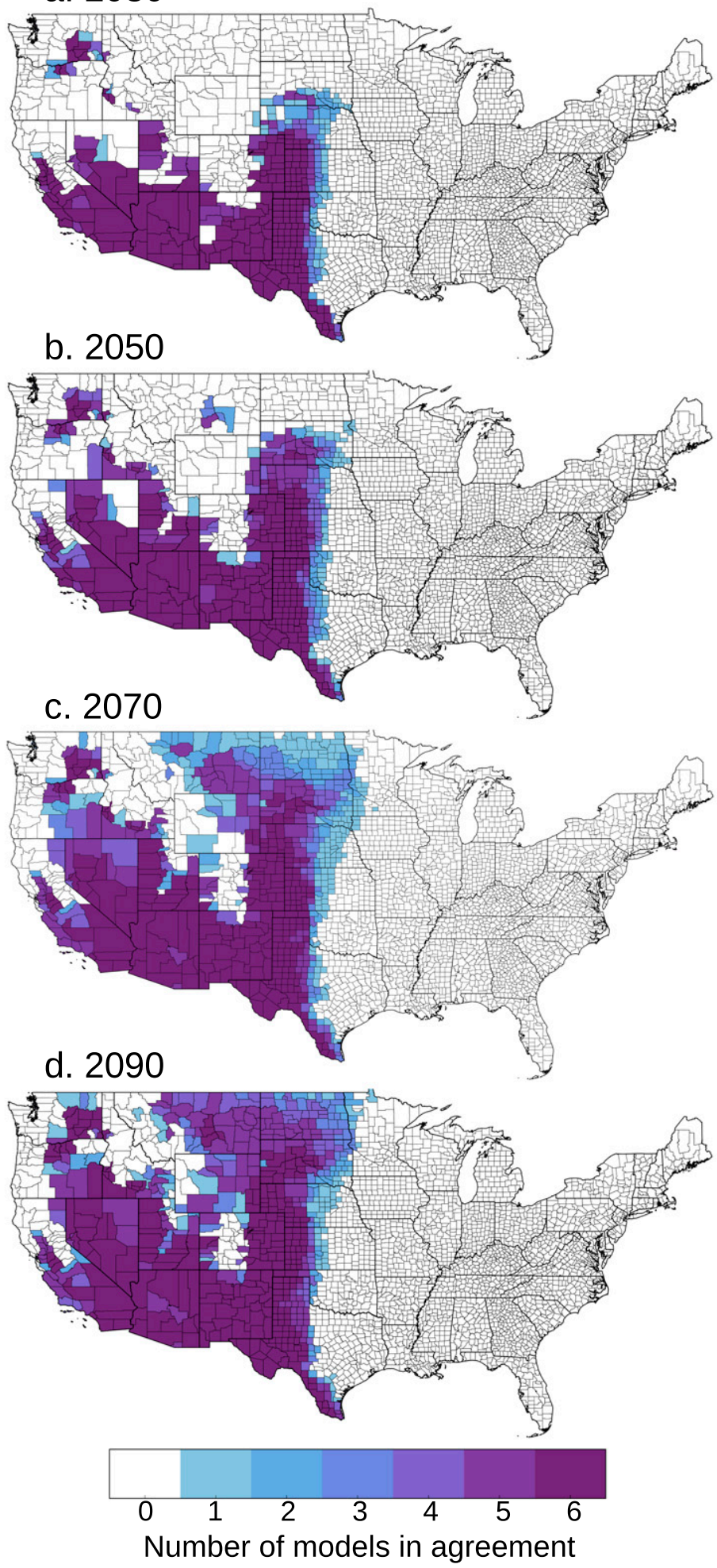

FIG. 3. The number of Earth system models from the CIRA framework $(n=6)$ in agreement that each county may be endemic to valley fever for the RCP8.5 climate scenario in years (a) 2030, (b) 2050, (c) 2070, and (d) 2090, defined by meeting both the mean annual temperature and mean annual precipitation thresholds following Gorris et al. (2019). There is consistent agreement that the southwestern United States and southern Great Plains will remain endemic through time. There is the largest spread between model projections in the extent of the northward expansion of endemicity in 2070, but by 2090 most models estimate the endemic area will reach the U.S.-Canada border. 
TABLE 1. Number of endemic counties and states (in parentheses) in the United States predicted for the RCP8.5 climate scenario for each Earth system model for 2030, 2050, 2070, and 2090. The PRISM reference (mean 2000-15) is 217 counties and 12 states.

\begin{tabular}{cccccccr}
\hline \hline & CanESM2 & CCSM4 & GFDL CM3 & GISS-E2-R & HadGEM2-ES & MIROC5 & Multimodel mean \\
\hline 2030 & $298(16)$ & $339(16)$ & $268(16)$ & $253(15)$ & $328(17)$ & $353(16)$ & $307(16.0)$ \\
2050 & $340(18)$ & $415(18)$ & $339(18)$ & $311(16)$ & $448(19)$ & $374(18)$ & $371(17.8)$ \\
2070 & $380(20)$ & $421(19)$ & $389(19)$ & $337(17)$ & $509(20)$ & $567(21)$ & $434(19.3)$ \\
2090 & $414(19)$ & $480(20)$ & $472(19)$ & $364(18)$ & $511(20)$ & $584(20)$ & $471(19.3)$ \\
\hline
\end{tabular}

growth and by $46 \%$ disregarding changes in population (Table S5 in the online supplemental material). The difference in percent increase between constant population and population growth scenarios highlights the importance of both climate change and future changes in human population causing higher disease burden.

Individual Earth system model projections of the number of potential valley fever cases varied and aligned with the characteristic of each model (Fig. 5). For example, GISS-E2-R has the most moderate growth in temperature, resulting in the second lowest estimated number of valley fever cases by 2090 . On the other hand, HadGEM-ES and GFDL CM2 include the highest future temperature scenarios, resulting in the largest number of predicted valley fever cases by 2090. CanESM2 is characterized by high temperatures, but also increases in precipitation across much of the western half of the United States throughout the century; this results in the lowest number of valley fever cases estimated for 2090 across the six models. Five out of the six models project a continuous increase in cases per year from baseline to 2090 when both accounting for increases in population and without population growth (Fig. 5).

\section{c. Health impacts analysis and economic valuation}

We used our economic valuation framework (section $2 \mathrm{~g}$ ) and our projections of the number of valley fever cases throughout the twenty-first century (Fig. 5) to quantify the economic burden from this disease. The total economic costs associated with valley fever health outcomes are displayed in Fig. 6. The annual value of total costs for the reference period (2010) is estimated to be $\$ 3.9$ billion per year (2015 dollars). Under RCP8.5 with population growth modeled by ICLUSv2, the average annual cost across the six Earth systems models is estimated at $\$ 6.7$ billion in $2030, \$ 10.2$ billion in $2050, \$ 13.9$ billion in 2070 , and $\$ 18.5$ billion in 2090 (all 2015 dollars; Table 4). The same model holding population constant at 2010 levels projects average annual cost across the six models to be $\$ 5.3$ billion in 2030 , $\$ 6.9$ billion in 2050, $\$ 8.4$ billion in 2070 , and $\$ 10.4$ billion in 2090 (all 2015 dollars; Table 4). Between 2010 and 2090, the average annual costs are expected to increase by $2.0 \%$ per year under the population growth scenario and $1.3 \%$ per year without population growth.

Likewise, under RCP4.5, which assumes more moderate greenhouse gas emissions over time, and under the ICLUSv2 population growth scenario, the average annual cost across the six Earth system models is slightly lower: $\$ 6.4$ billion in 2030 , $\$ 9.5$ billion in $2050, \$ 12.2$ billion in 2070 , and $\$ 15.2$ billion in 2090 (all 2015 dollars; Table S6 in the online supplemental material). With population levels held constant at 2010 levels, RCP4.5 projects even lower total annual costs: $\$ 5.1$ billion in 2030, \$6.4 billion in 2050, $\$ 7.3$ billion in 2070, and $\$ 8.4$ billion in 2090 (all 2015 dollars; Table S6). These costs suggest average annual increases of $1.8 \%$ per year with population growth and $1.0 \%$ without population growth.

The results also reveal important differences across the six Earth system models, where differences become more evident after 2050 and more pronounced for RCP8.5 (Table 4; supplemental Table S6). In the RCP8.5 scenario, similar to the estimated number of cases by Earth system model, HadGEM2ES and GFDL CM3 consistently estimate the highest annual costs in each future year, reaching $\$ 11-12$ billion in 2090 without population growth and \$21-23 billion in 2090 with population growth. At the low end, GISS-E2-R (with the most moderate temperature increase) estimates the lowest annual costs in the early years (2030 and 2050) while CanESM2 (with the highest late century precipitation projections) estimates the lowest annual costs in the later years (2070 and 2090).

Across the six Earth models and years, approximately 97\% to $98 \%$ of total costs in response to the RCP8.5 and RCP4.5 climate scenario are attributed to mortality (Table 5; Fig. 7). The next largest share of costs is attributed to cases that start in the emergency room and result in hospitalization (about $1.3 \%$ of total costs). For all outcomes except death, we incorporate both the direct and indirect productivity losses into these calculations. For reference, the total combined productivity losses across the four relevant outcome categories is about $0.2 \%$ of total overall costs.

TABLE 2. Number of millions of people living in endemic counties in the United States based on the ICLUSv2 future population estimates and 2010 constant population (in parentheses) projected for the RCP8.5 climate scenario for each Earth system model for 2030, 2050, 2070, and 2090. The PRISM reference (mean 2000-15) is 48.8 million people.

\begin{tabular}{rccccccr}
\hline \hline & CanESM2 & CCSM4 & GFDL CM3 & GISS-E2-R & HadGEM2-ES & MIROC5 & Multimodel mean \\
\hline 2030 & $64.7(51.6)$ & $66.2(52.7)$ & $65.8(52.5)$ & $62.7(50.1)$ & $63.9(51.0)$ & $66.7(53.2)$ & $65.0(51.9)$ \\
2050 & $73.0(50.2)$ & $75.8(52.4)$ & $82.3(56.7)$ & $77.0(52.4)$ & $83.6(57.5)$ & $83.8(57.4)$ & $79.2(54.4)$ \\
2070 & $57.0(36.2)$ & $92.4(56.9)$ & $87.7(54.3)$ & $87.9(53.6)$ & $96.7(59.7)$ & $96.2(59.0)$ & $86.3(53.3)$ \\
2090 & $61.0(36.2)$ & $99.2(57.1)$ & $104.4(59.6)$ & $94.7(54.4)$ & $98.8(57.0)$ & $107.0(61.1)$ & $94.2(54.2)$ \\
\hline
\end{tabular}


a. 2030
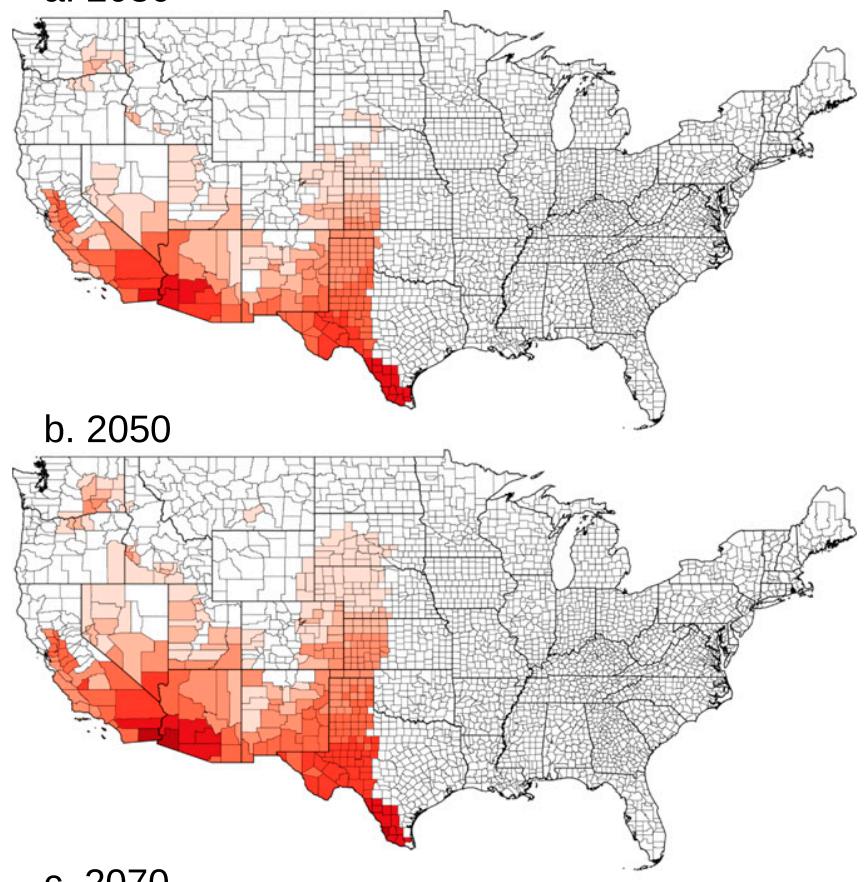

C. 2070
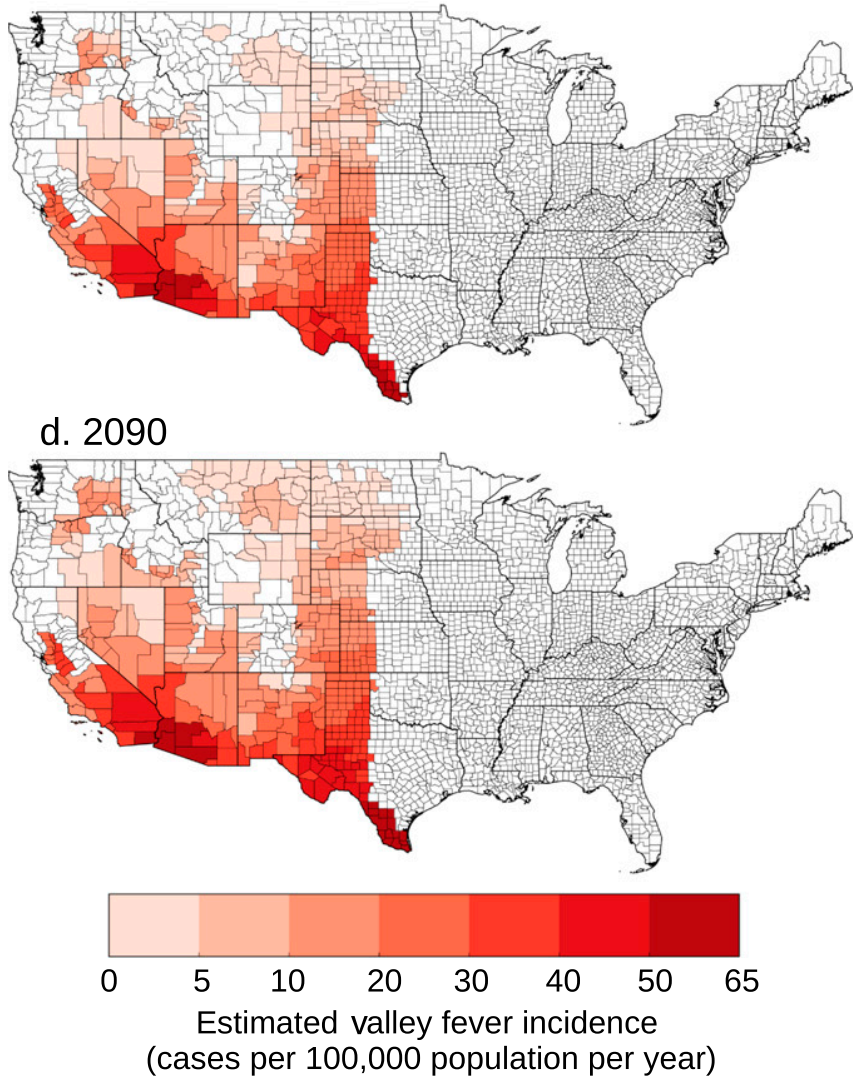

FIG. 4. We used an OLS regression model to estimate future disease incidence for the counties projected to be endemic. We averaged the incidence projections between the six Earth system models and applied the incidence value to counties in which at least four of the six models agree may be endemic in that time period. Incidence for the RCP8.5 climate scenario for years (a) 2030, (b) 2050, (c) 2070, and (d) 2090 is highest in the extreme southwestern United States. Through time, incidence increases in the southwestern United States and the Great Plains. 
TABLE 3. The number of valley fever cases per year in the United States based on the ICLUSv2 future population estimates and 2010 constant population (in parentheses) projected for the RCP8.5 climate scenario for each Earth system model for 2030, 2050, 2070, and 2090. The PRISM reference (mean 2000-15) is 9621 cases per year.

\begin{tabular}{cccccccc}
\hline \hline & CanESM2 & CCSM4 & GFDL CM3 & GISS-E2-R & HadGEM2-ES & MIROC5 & Multimodel mean \\
\hline 2030 & $15209(12050)$ & $14890(11764)$ & $15129(11970)$ & $13245(10479)$ & $15164(11984)$ & $14819(11703)$ & $14743(11658)$ \\
2050 & $19945(13437)$ & $19093(12867)$ & $21601(14561)$ & $17772(11940)$ & $21397(14406)$ & $20591(13853)$ & $20067(13511)$ \\
2070 & $18043(11115)$ & $23978(14365)$ & $27604(16622)$ & $22562(13473)$ & $30026(18064)$ & $25749(15397)$ & $24660(14839)$ \\
2090 & $21811(12512)$ & $28931(16117)$ & $36803(20488)$ & $25137(13920)$ & $33916(19001)$ & $32477(18000)$ & $29846(16673)$ \\
\hline
\end{tabular}

For comparison, we also estimate the average cost per valley fever case (Table 5): $\$ 400,000$ in 2010, $\$ 450,000$ in 2030, $\$ 510,000$ in 2050, $\$ 560,000$ in 2070, and $\$ 620,000$ in 2090 (all in 2015 dollars), suggesting annual cost per case increases by about $0.5 \%$ per year. The increases in cost per case are not driven by increases in projected population, but instead by changes in the values assigned to avoiding the risk of premature mortality and productivity costs over time. Our projections of increases in the per case cost of valley fever are an important contributor to our estimations of total cost. For example, if we were to hold the total cost per case constant at $\$ 400,000$ (and ignore changes in income over time as it affects the VSL and the indirect productivity costs), estimates of the total health burden would increase more slowly: in 2050, the total cost of valley fever in response to the RCP8.5 climate change scenario would be about $\$ 8$ billion, and in 2090 about $\$ 12$ billion, or approximately $79 \%$ and $65 \%$ of the comparable estimates considering increases in the cost per case shown in Table 5, respectively (see Table S7 in the online supplemental material for details of the sensitivity test holding all per case costs constant).

\section{Discussion}

\section{a. Economic impacts of valley fever in response to climate change}

We found that the economic burden of valley fever in the United States may increase by $168 \%$ from our baseline cost estimate to 2090 in response to a high greenhouse gas emissions climate change scenario (RCP8.5), considering an increasing per case cost of valley fever but without accounting for population growth. Projected increases in human population will exacerbate these costs, potentially increasing the economic burden from our baseline cost estimate to 2090 by $380 \%$.

We found there are three variables that may contribute to the increase in economic burden of valley fever throughout the twenty-first century: 1) climate change, 2) population growth, and 3) economic growth, in particular, changes in the VSL. As temperatures warm throughout the western United States and precipitation levels stay the same or decrease, more counties may become endemic to valley fever and put a higher population at risk of contracting this disease. Furthermore, increases in human population will amplify the number of people at risk. Already, our estimations of the total number of people currently living within the valley fever endemic region for our baseline period (Table 2) is an underestimation of present day levels since all states in the western United States have experienced population growth from 2010 to 2019, especially the high valley fever incidence states of Arizona and California (14\% and $6 \%$ population growth, respectively; U.S. Census Bureau 2019). Last, our preferred approach to VSL and wage growth over time, consistent with federal guidance, are a contributing factor as well-if we held per case costs constant, estimates in 2050 would be about $79 \%$ of the primary estimates reported here, and in 2090 would be about $65 \%$ of our primary estimates of economic burden.

There are several additional direct and indirect health costs from valley fever that we were not able to consider in our economic valuation. We only consider nonfatal costs in the year of incidence, but not potential longer-term effects of the disease such as emergency room or hospital readmission. In a California study of hospitalized valley fever patients from 2000 to $2011,24 \%$ of patients initially hospitalized were readmitted and of those, $28 \%$ were readmitted at least 3 times (Sondermeyer et al. 2013). Our method for estimating indirect costs relies solely on information we can verify from hospital records on the length of hospital stays, and it seems very reasonable that lost work time and therefore indirect costs would be higher after hospital discharge, and could include sick leave and disability. Wilson et al. (2019) used an expert medical panel to estimate the duration and economic impact of postdischarge lost work time and productivity, and found that in the most severe cases (about two percent of total estimated cases) the extended indirect costs could exceed $\$ 1$ million. Some examples of other costs unaccounted for include quality of life costs and productivity losses from caretakers of valley fever patients.

\section{b. Economic impacts of valley fever in comparison to other climate change attributable damages}

Climate change is having impacts on the geographic extent, seasonality, human exposure, and other characteristics of human infections and diseases. There is a growing interest in quantifying and monetizing these impacts (Crimmins et al. 2016). Climate impacts on illnesses include changes in the range of mosquitoes and ticks that carry vector-borne diseases such as West Nile virus and Lyme disease, an increase in ocean temperatures that are hospitable to waterborne infections such as Vibrio vulnificus, and more intense precipitation events that can spread diseases such as cholera. However, the attribution and projection of these impacts can be a challenging task, as estimates of the effect of climate on the frequency of negative health endpoints such as mortality can be a function not only of 


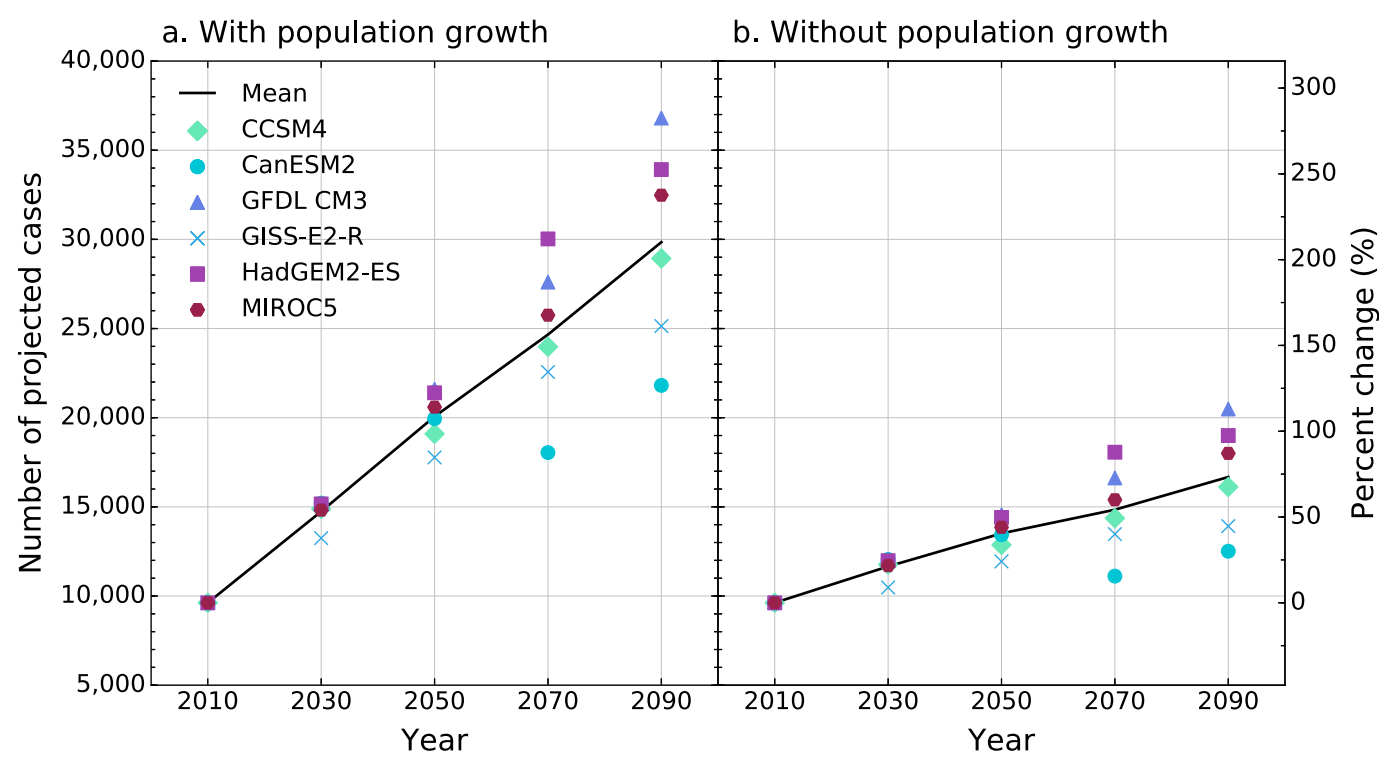

FIG. 5. The number of valley fever cases per year estimated for our baseline time period (mean 2000-15, denoted as 2010) and projected for the RCP8.5 climate scenario. We show a projection for each Earth system model for 2030, 2050, 2070, and 2090 with both (a) ICLUSv2 population estimates and (b) constant population scenarios (2010 population). The average of the six Earth system models is plotted as a black line.

the climate drivers (changes in temperature and precipitation at fine spatial and temporal scales), but also of responses of biological organisms to those drivers, changes in human behavior modifying exposure to the disease vectors, the efficacy of the healthcare system at preventing the worst outcomes from acquiring the disease, and the potential for health services to actually eradicate some diseases (such as malaria) from areas that would otherwise have a compatible climate.

Our study advances the scientific understanding of climaterelated health impacts by quantifying the impact of climate change on valley fever in terms of the spatial extent of the endemic region, the number of disease cases, and the resulting economic damages. It does so using the CIRA framework, which enables consistent comparisons between various climate impacts. Two relevant comparisons are the economic impacts of another environmental infectious disease-West Nile virus - and future impacts of increases in fine dust, which may correlate with increased exposure to Coccidioides spp., the fungal species that cause valley fever. West Nile virus is both the most widespread mosquito-borne disease in the United States and the largest cause of mosquito-borne disease in humans in the United States, with a few thousand cases reported per year (vector-borne disease chapter, Crimmins et al. 2016). Belova et al. (2017) projected that under a high greenhouse gas emission scenario RCP8.5, climate change could lead to an increase of 2500 West Nile virus neuroinvasive disease cases by the end of the century (average of 2080-99). This would result in a monetized impact of $\$ 2.6$ billion (2015 dollars). Although the endemic region to valley fever will be limited to only the western half of the United States, our projected number of valley fever cases assuming a constant population is about triple that of West Nile virus, and our study projects a sixfold larger monetized effect. The most widespread tick-borne illness in the United States is
Lyme disease, with 30000 reported cases per year, but no estimates of future incidence have yet been done consistent with the CIRA framework.

Another relevant climate and health comparison is the effect of aridity on the inhalation of fine dust in the southwestern United States. Fine dust may carry Coccidioides ssp. spores: outbreaks of valley fever have been associated with both local exposure to dust, such as that from construction work (Wilken et al. 2015), and regional dust events such as dust storms (Tong et al. 2017; Williams et al. 1979). Achakulwisut et al. (2019) projected that damages related to dust-attributable cardiovascular mortality and asthma could increase from $\$ 13{\text { billion } \mathrm{yr}^{-1}}^{-1}$

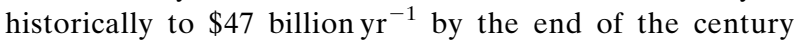
(average of 2080-99), including future changes in population. This estimate is about double the estimated future costs of valley fever in this study. Our study accounted for local changes in aridity by proxy by accounting for mean annual levels of precipitation. A mechanism for incorporating increased levels of fine dust into our economic impact estimated of valley fever may increase our health impact estimations; however, the statistical relationship between levels of fine dust and valley fever cases remains uncertain (Comrie 2005; Gorris et al. 2018; Komatsu et al. 2003; Park et al. 2005; Weaver and Kolivras 2018).

\section{c. Steps to refining the role of climate change and environmental conditions on valley fever disease dynamics}

In addition to the mean annual number of valley fever cases increasing, climate change may also impact the number of disease outbreaks and the severity of each valley fever season. Outbreaks and years with exceptionally high case counts may be driven by interannual variations in climate or short-term 
a. RCP4.5

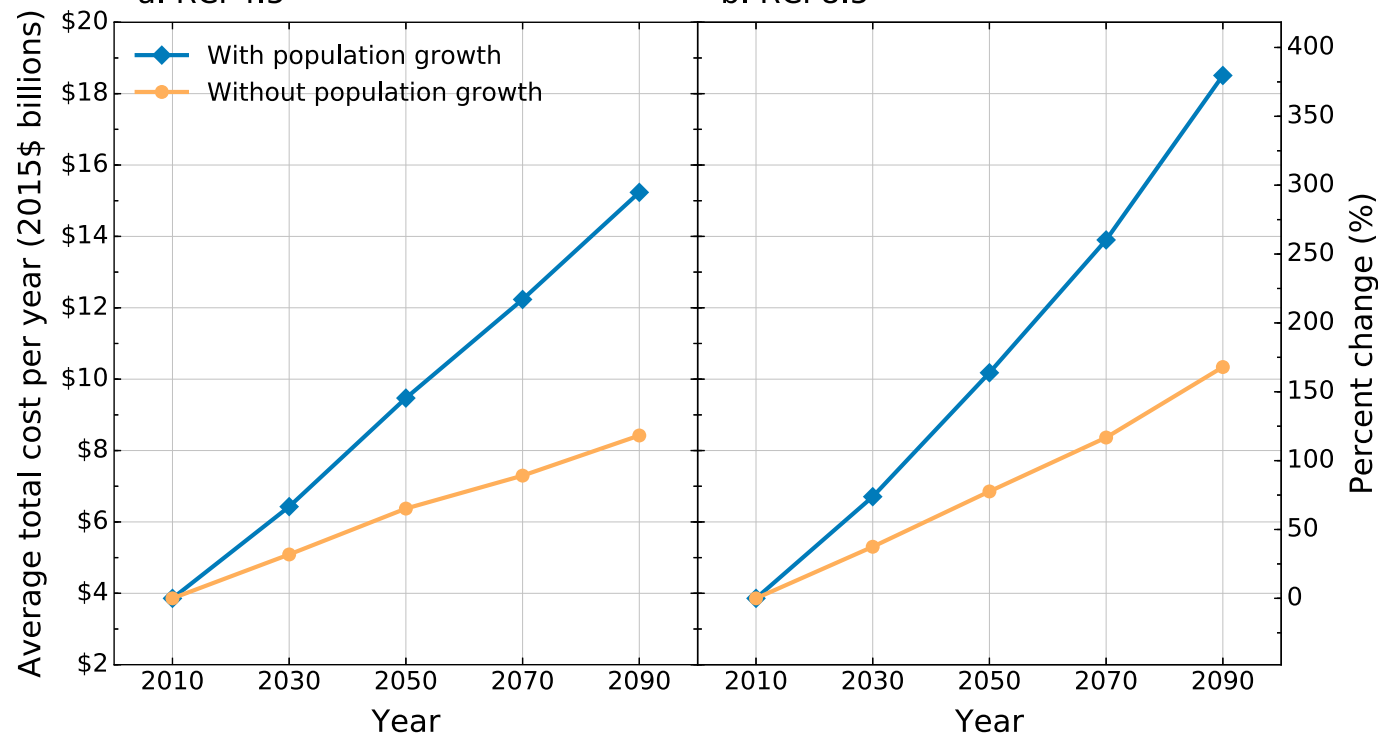

FIG. 6. Average total economic cost per year (2015 dollars, billions) of valley fever estimated for our baseline time period (mean 2000-15, denoted as 2010) and projections with ICLUSv2 population growth estimates and constant population (2010 population) for both the (a) RCP4.5 and (b) RCP8.5 climate scenarios. The economic cost values represent averages across the six Earth system models. Both RCP4.5 and RCP8.5 incorporate the same time-varying total cost per valley fever case, as reported in Table 5. Considering population growth, the RCP8.5 climate scenario may result in a total economic cost of valley fever that is $22 \%$ larger than the RCP 4.5 climate scenario by 2090 .

dust events (Colson et al. 2017; Comrie 2005; Park et al. 2005; Wilken et al. 2015; Williams et al. 1979). In parts of the southwestern United States, climate change will increase the number of intense rainstorms followed by longer periods of drought, with little change in the overall amount of rainfall (Polade et al. 2017; Swain et al. 2018); this may cause a large growth in Coccidioides ssp. during the wet season and increase spore emissions during the periods of drought, leading to more disease cases. Climate change may also increase the number of dust storms, which are known to carry Coccidioides spp. spores (Tong et al. 2017).

Our projections do not consider the impact that seasonal to annual variability in climate may have on disease burden, but rather estimate the mean burden. As more valley fever case data become available, the possibility of time series analyses estimating the number of interannual disease cases may allow for estimates of the severity of each valley fever season. Furthermore, improved valley fever surveillance in states our model suggests may be currently endemic or endemic in the near future would help refine the role climate plays on structuring the endemic region; the states our model estimates as currently endemic that currently do not report include Colorado, Idaho, Kansas, Oklahoma, and Texas (CDC 2019b).

Currently, our method for projecting which counties may be endemic to valley fever in the future is limited to using disease case data at the county-level as a proxy for fungal presence due to the sparse data available on where Coccidioides ssp. lives in the environment. Efforts to systematically map the presence of Coccidioides spp. in both soils and atmospheric dust throughout the western United States is an important next step toward developing a mechanistic model, which could separately simulate Coccidioides spp. abundance, transmission efficiency, and host heterogeneity. Our current model does not consider host demographics, which also effects valley fever case burden; for example, immunocompromised persons are more susceptible to contracting valley fever (Bercovitch et al. 2011;

TABLE 4. The total annual cost of valley fever in the United States in billions of dollars (2015 dollars) based on the ICLUSv2 future population estimates and 2010 constant population (in parentheses) projected for the RCP8.5 climate scenario for each Earth system model for 2030, 2050, 2070, and 2090. The PRISM reference (mean 2000-15) is \$3.86 billion.

\begin{tabular}{|c|c|c|c|c|c|c|c|}
\hline & CanESM2 & CCSM4 & GFDL CM3 & GISS-E2-R & HadGEM2-ES & MIROC5 & Multimodel mean \\
\hline 2030 & $\$ 6.92(\$ 5.48)$ & $\$ 6.77(\$ 5.35)$ & $\$ 6.88(\$ 5.45)$ & $\$ 6.03(\$ 4.77)$ & $\$ 6.90(\$ 5.45)$ & $\$ 6.74(\$ 5.32)$ & $\$ 6.71(\$ 5.30)$ \\
\hline 2050 & $\$ 10.12(\$ 6.82)$ & $\$ 9.69(\$ 6.53)$ & $\$ 10.96(\$ 7.39)$ & $\$ 9.02(\$ 6.06)$ & $\$ 10.85(\$ 7.31)$ & $\$ 10.45(\$ 7.03)$ & $\$ 10.18(\$ 6.85)$ \\
\hline 2070 & $\$ 10.17(\$ 6.27)$ & $\$ 13.52(\$ 8.10)$ & $\$ 15.56(\$ 9.37)$ & $\$ 12.72(\$ 7.59)$ & $\$ 16.93(\$ 10.18)$ & $\$ 14.51(\$ 8.68)$ & $\$ 13.90(\$ 8.36)$ \\
\hline 2090 & $\$ 13.53(\$ 7.76)$ & $\$ 17.94(\$ 9.99)$ & $\$ 22.82(\$ 12.71)$ & $\$ 15.59(\$ 8.63)$ & $\$ 21.03(\$ 11.78)$ & $\$ 20.14(\$ 11.16)$ & $\$ 18.51(\$ 10.34)$ \\
\hline
\end{tabular}


TABLE 5. Average economic costs of valley fever by outcome, overall, and cost per case (millions of 2015 dollars). Note: This is the average across the six Earth system models with population growth scenario (ICLUSv2). Each outcome includes both direct and indirect (i.e., productivity losses) costs.

\begin{tabular}{|c|c|c|c|c|c|}
\hline Outcome & Future scenario & 2030 & 2050 & 2070 & 2090 \\
\hline \multirow[t]{2}{*}{ Hospitalization } & $\mathrm{RCP} 4.5$ & $\$ 63.6$ & $\$ 86.9$ & $\$ 105.0$ & $\$ 124.1$ \\
\hline & RCP8.5 & $\$ 66.3$ & $\$ 93.4$ & $\$ 119.3$ & $\$ 150.8$ \\
\hline \multirow[t]{2}{*}{ Emergency room and then discharge } & $\mathrm{RCP} 4.5$ & $\$ 3.9$ & $\$ 6.4$ & $\$ 9.1$ & $\$ 12.5$ \\
\hline & RCP8.5 & $\$ 4.0$ & $\$ 6.8$ & $\$ 10.3$ & $\$ 15.2$ \\
\hline \multirow[t]{2}{*}{ Emergency room and then hospital } & $\mathrm{RCP} 4.5$ & $\$ 83.7$ & $\$ 111.4$ & $\$ 130.6$ & $\$ 149.3$ \\
\hline & RCP8.5 & $\$ 87.3$ & $\$ 119.7$ & $\$ 148.4$ & $\$ 181.3$ \\
\hline \multirow[t]{2}{*}{ Physician's visit only } & $\mathrm{RCP} 4.5$ & $\$ 3.8$ & $\$ 6.3$ & $\$ 9.1$ & $\$ 12.7$ \\
\hline & $\mathrm{RCP} 8.5$ & $\$ 3.9$ & $\$ 6.8$ & $\$ 10.4$ & $\$ 15.4$ \\
\hline \multirow[t]{2}{*}{ Death } & $\mathrm{RCP} 4.5$ & $\$ 6,273.7$ & $\$ 9,259.1$ & $\$ 11,979.9$ & $\$ 14,935.7$ \\
\hline & RCP8.5 & $\$ 6,545.7$ & $\$ 9,953.0$ & $\$ 13,612.4$ & $\$ 18,146.2$ \\
\hline \multirow[t]{2}{*}{ Total cost } & $\mathrm{RCP} 4.5$ & $\$ 6,428.6$ & $\$ 9,470.0$ & $\$ 12,233.6$ & $\$ 15,234.2$ \\
\hline & RCP8.5 & $\$ 6,707.3$ & $\$ 10,179.8$ & $\$ 13,900.7$ & $\$ 18,508.9$ \\
\hline \multirow[t]{2}{*}{ Total cost per case } & $\mathrm{RCP} 4.5$ & $\$ 0.45$ & $\$ 0.51$ & $\$ 0.56$ & $\$ 0.62$ \\
\hline & RCP8.5 & $\$ 0.45$ & $\$ 0.51$ & $\$ 0.56$ & $\$ 0.62$ \\
\hline
\end{tabular}

Blair and Logan, 2001; Rosenstein et al. 2001; Woods et al. 2000) and disseminated cases are more frequent in non-white races (Crum et al. 2004; Rosenstein et al. 2001).

More work is also needed on estimating the full economic burden of valley fever incidence, particularly over long time frames. Future research could focus on better identifying trends in mortality rates and treatment costs over time, and whether these trends might provide a basis for long-term projections of these rates and costs. Additional work is needed to more fully document the long-term direct medical and indirect productivity costs of severe, but nonfatal cases as well, which we likely underestimate here. Finally, it remains critically important to a. Percent of cases

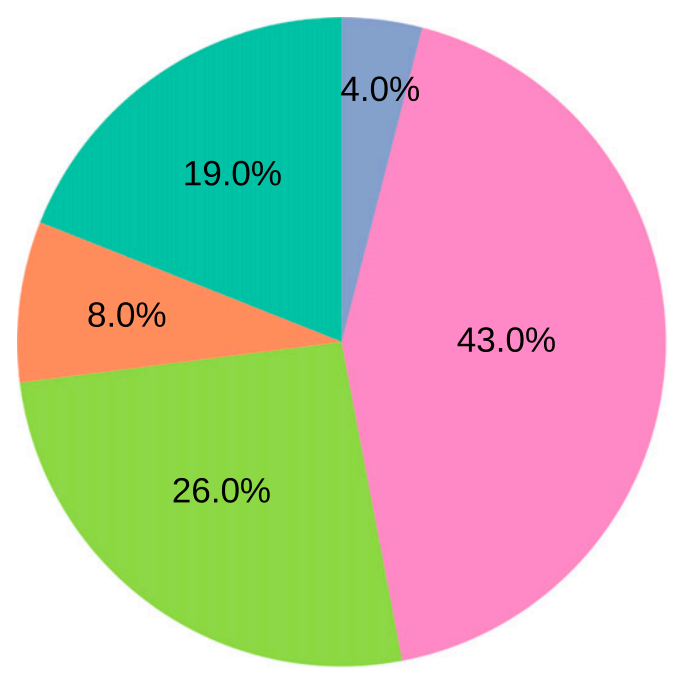

b. Percent of costs

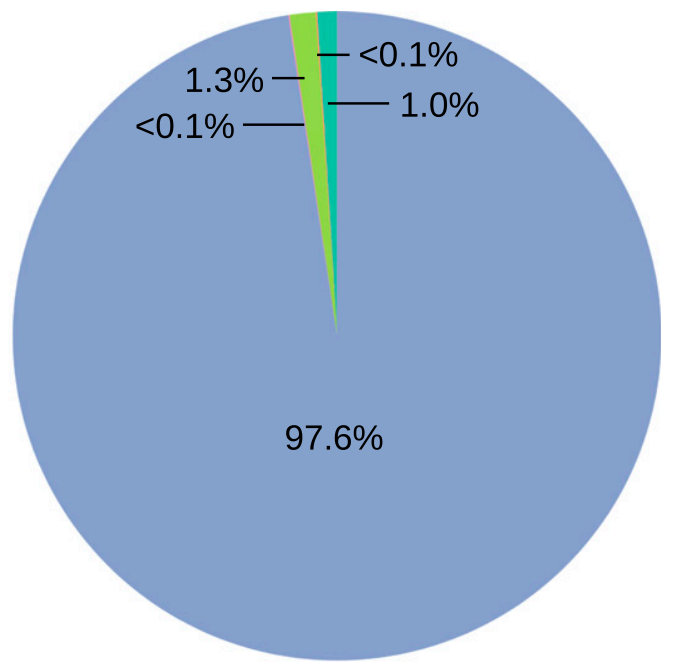

\section{Direct hospitalization ER visit then discharge}

\section{ER visit then hospital admittance} Physician visit

FIG. 7. Percent of cases that result in each health outcome (i.e., direct hospitalizations, emergency room and then discharge, emergency room and then hospital admittance, physician's visits, and death) vs percent of total economic costs associated with each health outcome. The percent of cases data are derived from historical rates from HCUPnet, NIS, NEDS, and Gorris et al. (2019) and remain constant across all years, as explained in section $2 \mathrm{~g}$. The percent of costs data are averaged across years and RCPs and account for population growth. 
clarify the full impact of mortality on society-consistent with federal guidance and appropriate for contexts where disease prevention is an option, we adopt here a willingness-to-pay approach that is designed to capture individuals preferences for life-saving interventions. Other literatures (including Wilson et al. 2019) adopt a human capital approach that values fatal consequences at the current wage rate. This is likely a conservative estimate of the loss to society from a potentially fatal disease such as valley fever.

\section{Conclusions}

We used projections of valley fever disease incidence driven by the CIRA framework developed by the EPA to quantify the economic impacts of valley fever in the United States in response to climate change. We found the area endemic to valley fever will expand northward in response to climate change from 217 counties for our 2000-15 baseline time period to 471 counties by 2090 for the RCP8.5 climate scenario. Considering the ICLUSv2 population projections, this may put an additional 45.4 million people at risk for contracting valley fever. In concert, the annual average total costs of valley fever may increase by a factor of 5 in the twenty-first century, from an estimated $\$ 3.9$ billion per year in 2010 to $\$ 18.5$ billion per year by 2090 (all 2015 dollars). However, following the RCP4.5 climate scenario could reduce the health and economic impacts of valley fever. For the RCP4.5 climate and considering population growth following ICLUSv2 projections, total mean annual costs may reach $\$ 15.2$ billion per year by 2090 , representing an $18 \%$ reduction relative to the RCP8.5 climate scenario. Our work quantifying the economic impacts of valley fever in the United States contributes to the broader effort to monetize climate change attributable damages and provide projections for disease mitigation programs.

Acknowledgments. This research was funded by the U.S. Environmental Protection Agency (EPA) under contract EP-D-14-031. The views expressed in this document are those of the authors and do not necessarily reflect those of their affiliated institutions, including the EPA and Los Alamos National Laboratory. We thank the Arizona Department of Health Services, the California Department of Public Health, the New Mexico Department of Health, the Nevada Department of Health and Human Services, and the Utah Department of Health for providing us with valley fever case data from their respective state health agencies. The authors also acknowledge and are grateful for the important contributions of their colleagues: Andrew Cahill, Zoe Kerrich, William Raich, and Robert Paterson.

Data availability statement. A subset of the valley fever case data approved for sharing by the state health agencies is available online (https://github.com/valleyfever/valleyfevercasedata; Gorris et al. 2020). Because of the sensitive nature of public health data, the remaining valley fever data may be obtained with a data-user agreement upon request from the affiliated state health agencies.

\section{REFERENCES}

Achakulwisut, P., and Coauthors, 2019: Effects of increasing aridity on ambient dust and public health in the U.S. southwest under climate change. Geohealth, 3, 127-144, https://doi.org/ 10.1029/2019GH000187.

Belova, A., D. Mills, R. Hall, and A. Juliana, A. Crimmins, C. Barker, and R. Jones, 2017: Impacts of increasing temperature on the future incidence of West Nile neuroinvasive disease in the United States. Amer. J. Climate Change, 6, 166-216, https:// doi.org/10.4236/ajcc.2017.61010.

Bercovitch, R. S., A. Catanzaro, B. S. Schwartz, D. Pappagianis, D. H. Watts, and N. M. Ampel, 2011: Coccidioidomycosis during pregnancy: A review and recommendations for management. Clin. Infect. Dis., 53, 363-368, https://doi.org/10.1093/ $\mathrm{cid} / \mathrm{cir} 410$.

Bierwagen, B. G., D. M. Theobald, C. R. Pyke, A. Choate, P. Groth, J. V. Thomas, and P. Morefield, 2010: National housing and impervious surface scenarios for integrated climate impact assessments. Proc. Natl. Acad. Sci. USA, 107, 20 887-20 892, https://doi.org/10.1073/pnas.1002096107.

Blair, J. E., and J. L. Logan, 2001: Coccidioidomycosis in solid organ transplantation. Clin. Infect. Dis., 33, 1536-1544, https:// doi.org/10.1086/323463.

CDC, 2019a: Valley fever maps. Accessed 25 November 2019, https://www.cdc.gov/fungal/diseases/coccidioidomycosis/ maps.html.

, 2019b: Valley fever (coccidioidomycosis) statistics. Accessed 25 November 2019, https:/www.cdc.gov/fungal/diseases/ coccidioidomycosis/statistics.html.

- 2019c: CDC WONDER Underlying Cause of Death (UCD) and Multiple Cause of Death (MCD) mortality databases. Accessed 16 August 2019, https://wonder.cdc.gov/.

Chen, Y.-H. H., S. Paltsev, J. M. Reilly, J. F. Morris, and M. H. Babiker, 2015: The MIT EPPA6 Model: Economic growth, energy use, and food consumption. MIT Joint Program on the Science and Policy of Global Change Rep. 278, 46 pp., https:// globalchange.mit.edu/sites/default/files/MITJPSPGC_Rpt278.pdf.

Collins, W. J., and Coauthors, 2011: Development and evaluation of an Earth-system model-HadGEM2. Geosci. Model Dev., 4, 1051-1075, https://doi.org/10.5194/gmd-4-1051-2011.

Colson, A. J., L. Vredenburgh, R. E. Guevara, N. P. Rangel, C. T. Kloock, and A. Lauer, 2017: Large-scale land development, fugitive dust, and increased coccidioidomycosis incidence in the Antelope Valley of California, 1999-2014. Mycopathologia, 182, 439-458, https://doi.org/10.1007/s11046-016-0105-5.

Comrie, A. C., 2005: Climate factors influencing coccidioidomycosis seasonality and outbreaks. Environ. Health Perspect., 113, 688-692, https://doi.org/10.1289/ehp.7786.

Crimmins, A., and Coauthors, Eds., 2016: The Impacts of Climate Change on Human Health in the United States: A Scientific Assessment. A. Crimmins et al., Eds., U.S. Global Change Research Program, 312 pp., https://dx.doi.org/10.7930/J0R49NQX.

Crum, N. F., E. R. Lederman, C. M. Stafford, J. S. Parrish, and M. R. Wallace, 2004: Coccidioidomycosis: A descriptive survey of a reemerging disease, clinical characteristics and current controversies. Medicine, 83, 149-175, https://doi.org/ 10.1097/01.md.0000126762.91040.fd.

Daly, C., M. Halbleib, J. I. Smith, W. P. Gibson, M. K. Doggett, G. H. Taylor, J. Curtis, and P. P. Pasteris, 2008: Physiographically sensitive mapping of climatological temperature and precipitation across the conterminous United States. Int. J. Climatol., 28, 2031-2064, https://doi.org/ 10.1002/joc. 1688 . 
Donner, L. J., and Coauthors, 2011: The dynamical core, physical parameterizations, and basic simulation characteristics of the atmospheric component AM3 of the GFDL Global Coupled Model CM3. J. Climate, 24, 3484-3519, https://doi.org/10.1175/ 2011JCLI3955.1.

Eicker, F., 1967: Limit theorems for regressions with unequal and dependent errors. Theory of Statistics, L. M. Le Cam and J. Neyman, Eds., Vol. I, Proceedings of the Fifth Berkeley Symposium on Mathematical Statistics and Probability, University of California Press, 59-82.

EPA, 2014: Guidelines for preparing economic analyses. U.S. EPA National Center for Environmental Economics Office of Policy Doc., 302 pp., https:/www.epa.gov/sites/production/ files/2017-08/documents/ee-0568-50.pdf.

, 2015: Climate change in the United States: Benefits of global action. U.S. EPA Office of Atmospheric Programs Rep., 96 pp., https://www.epa.gov/sites/production/files/2015-06/documents/ cirareport.pdf.

__, 2017a: Multi-model framework for quantitative sectoral impacts analysis: A technical report for the Fourth National Climate Assessment. U.S. EPA Rep., 277 pp., https://cfpub.epa.gov/si/si_ public_file_download.cfm?p_download_id $=537327 \&$ Lab $=$ OAP.

_ $2017 \mathrm{~b}$ : Updates to the demographic and spatial allocation models to produce Integrated Climate and Land Use Scenarios (ICLUS) Version 2. U.S. EPA Office of Research and Development Doc., 134 pp., http://ofmpub.epa.gov/eims/ eimscomm.getfile?p_download_id=530694.

—_, 2018a: BenMAP-CE User's Manual. U.S. EPA Doc., 471 pp., https:/www.epa.gov/sites/production/files/2015-04/documents/ benmap-ce_user_manual_march_2015.pdf.

—_, 2018b: BenMAP Community Edition v 1.4.14. EPA. https:// www.epa.gov/benmap/benmap-community-edition.

Frenzen, P. D., T. L. Riggs, J. C. Buzby, T. Breuer, T. Roberts, D. Voetsch, S. Reddy, and FoodNet Working Group, 1999: Salmonella cost estimate updated using FoodNet data. Food Rev./Natl. Food Rev., 22, 10-15, https://doi.org/10.22004/ ag.econ.266212.

Gent, P. R., and Coauthors, 2011: The Community Climate System Model Version 4. J. Climate, 24, 4973-4991, https://doi.org/ 10.1175/2011JCLI4083.1.

Gorris, M. E., L. A. Cat, C. S. Zender, K. K. Treseder, and J. T. Randerson, 2018: Coccidioidomycosis dynamics in relation to climate in the southwestern United States. Geohealth, 2, 6-24, https://doi.org/10.1002/2017GH000095.

_, K. K. Treseder, C. S. Zender, and J. T. Randerson, 2019: Expansion of coccidioidomycosis endemic regions in the United States in response to climate change. Geohealth, 3, 308-327, https://doi.org/10.1029/2019GH000209.

—, L. A. Cat, M. Matlock, O. A. Ogunseitan, K. K. Treseder, J. T. Randerson, and C. S. Zender, 2020: Coccidioidomycosis (Valley fever) case data for the southwestern United States. Open Health Data, 7, 1-4, https://doi.org/10.5334/ohd.31.

Hayhoe, K., and Coauthors, 2018: Our changing climate.

Impacts, Risks, and Adaptation in the United States: Fourth National Climate Assessment, Vol. II, D. R. Reidmiller et al., Eds., U.S. Global Change Research Program, 72-144, https:// doi.org/10.7930/NCA4.2018.CH2

Hoffmann, S., M. B. Batz, and J. G. Morris Jr., 2012: Annual cost of illness and quality-adjusted life year losses in the United States due to 14 foodborne pathogens. J. Food Prot., 75, 1292-1302, https://doi.org/10.4315/0362-028X.JFP-11-417.

Huber, P. J., 1967: The behavior of maximum likelihood estimates under non-standard conditions. Theory of Statistics, L. M.
Le Cam and J. Neyman, Eds., Vol. I, Proceedings of the Fifth Berkeley Symposium on Mathematical Statistics and Probability, University of California Press, 221-233.

Komatsu, K. V. Vaz, C. McRill, and T. Colman, 2003: Increase in coccidioidomycosis-Arizona, 1998-2001. MMWR Morb. Mortal. Wkly. Rep., 56, 109-112.

Martinich, J., and A. Crimmins, 2019: Climate damages and adaptation potential across diverse sectors of the United States. Nat. Climate Change, 9, 397-404, https://doi.org/10.1038/s41558019-0444-6.

Moss, R. H., and Coauthors, 2010: The next generation of scenarios for climate change research and assessment. Nature, 463, 747756, https://doi.org/10.1038/nature08823.

mate action: A framework for sustained assessment. Wea. Climate Soc., 11, 465-487, https://doi.org/10.1175/WCAS-D18-0134.1.

Nguyen, C., B. M. Barker, S. Hoover, D. E. Nix, N. M. Ampel, J. A. Frelinger, M. J. Orbach, and J. N. Galgiani, 2013: Recent advances in our understanding of the environmental, epidemiological, immunological, and clinical dimensions of coccidioidomycosis. Clin. Microbiol. Rev., 26, 505-525, https://doi.org/10.1128/ CMR.00005-13.

O’Neill, B. C., E. Kriegler, K. Riahi, K. L. Ebi, S. Hallegatte, T. R. Carter, R. Mathur, and D. P. vanVuuren, 2014: A new scenario framework for climate change research: The concept of shared socioeconomic pathways. Climatic Change, 122, 387-400, https://doi.org/10.1007/s10584-013-0905-2.

Park, B. J., and Coauthors, 2005: An epidemic of coccidioidomycosis in Arizona associated with climatic changes, 1998-2001. J. Infect. Dis., 191, 1981-1987, https://doi.org/10.1086/430092.

Pierce, D. W., D. R. Cayan, E. P. Maurer, J. T. Abatzoglou, and K. C. Hegewisch, 2015: Improved bias correction techniques for hydrological simulations of climate change. J. Hydrometeor., 16, 2421-2442, https://doi.org/10.1175/JHM-D-14-0236.1.

Polade, S. D., A. Gershunov, D. R. Cayan, M. D. Dettinger, and D. W. Pierce, 2017: Precipitation in a warming world: Assessing projected hydro-climate changes in California and other Mediterranean climate regions. Sci. Rep., 7, 10783, https:// doi.org/10.1038/s41598-017-11285-y.

Reidmiller, D. R., C. W. Avery, D. R. Easterling, K. E. Kunkel, K. L. M. Lewis, T. K. Maycock, and B. C. Stewart, Eds., 2018: Impacts, Risks, and Adaptation in the United States: Fourth National Climate Assessment, Vol. II, U.S. Global Change Research Program, 1515 pp., https://doi.org/10.7930/NCA4.2018.

Robinson, L. A., J. K. Hammitt, and L. O'Keefe, 2019: Valuing mortality risk reductions in global benefit-cost analysis. J. Benefit Cost Anal., 10, 15-50, https://doi.org/10.1017/bca.2018.26.

Rosenstein, N. E., and Coauthors, 2001: Risk factors for severe pulmonary and disseminated coccidioidomycosis: Kern County, California, 1995-1996. Clin. Infect. Dis., 32, 708-714, https:// doi.org/10.1086/319203.

Scallan, E., R. M. Hoekstra, F. J. Angulo, R. V. Tauxe, M.-A. Widdowson, S. L. Roy, J. L. Jones, and P. M. Griffin, 2011: Foodborne illness acquired in the United States-Major pathogens. Emerg. Infect. Dis., 17, 7-15, https://doi.org/10.3201/ eid1701.P11101.

Schmidt, G. A., and Coauthors, 2006: Present-day atmospheric simulations using GISS ModelE: Comparison to in situ, satellite, and reanalysis data. J. Climate, 19, 153-192, https:// doi.org/10.1175/JCLI3612.1.

Smith, C. E., and R. R. Beard, 1946: Varieties of coccidioidal infection in relation to the epidemiology and control of the 
diseases. Amer. J. Public Health Nations Health, 36, 13941402, https://doi.org/10.2105/AJPH.36.12.1394.

Sondermeyer, G., L. Lee, D. Gilliss, F. Tabnak, and D. Vugia, 2013: Coccidioidomycosis-associated hospitalizations, California, USA, 2000-2011. Emerg. Infect. Dis., 19, 1590-1597, https:// doi.org/10.3201/eid1910.130427.

Swain, D. L., B. Langenbrunner, J. D. Neelin, and A. Hall, 2018: Increasing precipitation volatility in twenty-first-century California. Nat. Climate Change, 8, 427-433, https://doi.org/ 10.1038/s41558-018-0140-y.

Taylor, K. E., R. J. Stouffer, and G. A. Meehl, 2011: An overview of CMIP5 and the experiment design. Bull. Amer. Meteor. Soc., 93, 485-498, https://doi.org/10.1175/BAMS-D-11-00094.1.

Tong, D. Q., J. X. Wang, T. E. Gill, H. Lei, and B. Wang, 2017: Intensified dust storm activity and valley fever infection in the southwestern United States. Geophys. Res. Lett., 44, 43044312, https://doi.org/10.1002/2017GL073524.

United Nations, 2015: World Population Prospects: The 2015 revision. UN Department of Economic and Social Affairs, accessed 26 November 2019, https://population.un.org/ wpp/.

U.S. Census Bureau, 2011: Intercensal estimates of the resident population for counties: April 1, 2000 to July 1, 2010. Accessed 26 November 2019, http://www.census.gov/data/tables/timeseries/demo/popest/intercensal-2000-2010-counties.html.

_- 2015: 2015 American Community Survey 1-Year Estimates Data Profiles, selected economic characteristics (Table ID DP03). Accessed 20 August 2020, https://data.census.gov/ cedsci/table? $\mathrm{q}=$ selected $\% 20$ economic $\% 20$ characteristics $\%$ 202015\&tid $=$ ACSDP1Y2015.DP03\&hidePreview $=$ false.

_ 2019: Cumulative estimates of resident population change for the United States, regions, states, and Puerto Rico and region and state rankings: April 1, 2010 to July 1, 2019. Accessed 14 June 2020, https://www.census.gov/data/tables/time-series/ demo/popest/2010s-national-total.html.

_ 2020: Annual resident population estimates, estimated components of resident population change, and rates of the components of resident population change for states and counties: April 1, 2010 to July 1, 2019. Accessed 20 August 2020, https://www.census.gov/data/datasets/time-series/demo/ popest/2010s-counties-total.html\#par_textimage_739801612.

USDA, 2014: Cost estimates of foodborne illnesses. USDA Economic Research Service, accessed 3 January 2020, https://www.ers.usda.gov/data-products/cost-estimates-offoodborne-illnesses.aspx.

van Vuuren, D. P., and Coauthors, 2011: RCP2.6: Exploring the possibility to keep global mean temperature increase below $2^{\circ}$ C. Climatic Change, 109, 95-116, https://doi.org/10.1007/ s10584-011-0152-3.

von Salzen, K., and Coauthors, 2013: The Canadian Fourth Generation Atmospheric Global Climate Model (CanAM4). Part I: Representation of physical processes. Atmos.-Ocean, 51, 104-125, https://doi.org/10.1080/07055900.2012.755610.

Watanabe, M., and Coauthors, 2010: Improved climate simulation by MIROC5: Mean states, variability, and climate sensitivity. J. Climate, 23, 6312-6335, https://doi.org/10.1175/2010JCLI3679.1.

Weaver, E. A., and K. N. Kolivras, 2018: Investigating the relationship between climate and valley fever (coccidioidomycosis). EcoHealth, 15, 840-852, https://doi.org/10.1007/s10393018-1375-9.

Wilken, J. A., and Coauthors, 2015: Coccidioidomycosis among workers constructing solar power farms, California, USA, 2011-2014. Emerg. Infect. Dis., 21, 1997-2005, https://doi.org/ 10.3201/eid2111.150129.

Williams, P. L., D. L. Sable, P. Mendez, and L. T. Smyth, 1979: Symptomatic coccidioidomycosis following a severe natural dust storm: An outbreak at the Naval Air Station, Lemoore, Calif. Chest, 76, 566-570, https://doi.org/10.1378/chest.76.5.566.

Wilson, L., and Coauthors, 2019: The rise of valley fever: Prevalence and cost burden of coccidioidomycosis infection in California. Int. J. Environ. Res. Public Health, 16, 1113, https://doi.org/ 10.3390/ijerph16071113.

Woods, C. W., and Coauthors, 2000: Coccidioidomycosis in human immunodeficiency virus-infected persons in Arizona, 19941997: Incidence, risk factors, and prevention. J. Infect. Dis., 181, 1428-1434, https://doi.org/10.1086/315401. 